[James, R. (2008). Achieving Social Inclusion and Universal Participation: Towards New Conceptions of Higher Education. New Zealand Annual Review of Education, 18, 47-63]

\section{Achieving Social Inclusion and Universal Participation: Towards New Conceptions of Higher Education}

\section{RICHARD JAMES}

\section{Abstract:}

The 2008 Review of Australian Higher Education established ambitious goals for widening university participation. This article analyses the challenges involved in transforming the Australian higher education system to achieve universal participation, including current patterns of educational disadvantage and the underlying causes for the persistent under-representation in universities of certain groups of Australians. The paper proposes a set of conditions needed for universal participation, and outlines the obstacles to embedding these in national and institutional policy and practice. While the analysis is framed within the present Australian political and social context, the conclusions are likely to be relevant for other national systems making the transition from mass to universal higher education.

$\mathrm{D}$

uring 2008 a sweeping review of Australian higher education was undertaken by a panel led by Professor Denise Bradley, former Vice-Chancellor of the University of South Australia. The review recommendations set bold targets for the expansion of access to Australian higher education and the achievement of equitable participation (DEEWR, 2008). Among 46 recommendations, the review proposed that the Australian Government set a national target of at least 40 percent of 25-34 year olds attaining a qualification at bachelor level or above by 2020 . This recommendation was a direct response to Australia's slipping performance against OECD nations in its extent of degree attainment, and the growing prevalence of 50 percent attainment targets among OECD nations. The proposed target represents a massive increase in degree completion from the base of 29 percent in 2008.

\section{Richard James}

The Bradley recommendations also addressed social inclusion. The review proposed that the Australian Government establish a national goal of 20 percent of higher education enrolments at undergraduate level being people from low socio-economic status backgrounds by 2020 . Again this was a bold target, with the present participation share for low SES Australians hovering at around 15 percent and remaining static for over a decade.

The two targets for expansion and equity were quickly endorsed by the Deputy Prime Minister, the Hon. Julia Gillard, with extension of the timeline for the bachelors completion target to 2025. The panel proposed that to support the achievement of the social inclusion target performance incentives be put in place:

... 4 percent of all funds for teaching will be directed to outreach and retention initiatives. All institutions in receipt of Commonwealth funds for teaching will be expected to establish initiatives to increase both the enrolment of, and success of, students from disadvantaged backgrounds. Part of this allocation will be directed to the support of outreach activities in communities with poor higher education participation rates. In partnership with schools and other education providers, higher education institutions will work to raise aspirations as well as provide academic mentoring and support. The bulk of the allocation will be distributed to institutions on the basis of their success in enrolling and graduating students from low socio-economic backgrounds. (DEEWR, 2008, p. xiv)

The Bradley review represents the first attempt to formulate a policy framework to encourage and enable universal participation in higher education in Australia. The recommendations link expansion tightly to equity and in doing so follow familiar international patterns, especially the widening participation policies of the UK (Corver, 2005). Importantly, the Bradley recommendations attempt to free-up and renew the equity policy framework for Australian higher education, which has remained virtually unchanged for 15 years (James \& McInnis, 2005).

In some ways the Bradley review report invites comparison with the 1998 Review of Higher Education Policy, Learning for Life (West, 1998), colloquially known as the West Review. The West Review's first recommendation argued for the need for "a commitment to establishment of a learning society in which all Australians, of whatever social, cultural and economic background, have access to a post-compulsory education of excellent value." The review proposed 
key changes as cornerstones for this goal, including achieving universal completion of secondary education, improving "first time access" to post-secondary education, and new student-centred funding arrangements - a voucher-like, lifelong learning entitlement.

The West Review argued that a student-centred funding model was necessary to achieve two complementary outcomes: the incentive to encourage students to choose their studies carefully, and, equally, encouragement for providers to compete vigorously in terms of the nature, price and quality of their offerings. The proposal drew widespread student protest and public concern and was dropped. Ten years on, Bradley took a softer line on student-centred funding, but nevertheless proposed a demand-driven system in which recognised providers should be free to enrol as many students as they wished and eligible students should enjoy an entitlement to Commonwealth supported higher education without time or cost limits.

The Bradley review's recommendations propose a partial move towards a less centrally regulated and arguably more responsive higher education system. The panel argued that in order to meet its proposed targets for expansion and social inclusion, a more deregulated system would be necessary. Further, the panel proposed that

...in a staged process, access to Commonwealth funds be made available to a wider range of eligible providers. But these funds will follow the student, not be allocated to the institution. All qualified individuals will have an entitlement to undertake an undergraduate qualification unlimited in duration or value. This is consistent with the need to broaden the base of higher education qualifications in the population and the need for skills upgrading over the life cycle. Such a system allows institutions flexibility to decide the courses they will offer and the number of students they will admit. This, combined with an entitlement for all qualified students, is the most responsive and appropriate policy option in circumstances where we must raise participation urgently and do so from among groups which have traditionally failed to participate. (DEEWR, 2008, p. xiv)

The Bradley panel presented the nation with a complex and confronting package of recommendations. While at the time of the review's release there was much policy detail to be worked through, initially the recommendations received a mixed public reaction, including criticism of the absence of crucial detail on the funding and mechanics of the student entitlement proposal and the processes for setting performance indicators for institutional equity performance.

\section{The Persistent Problem of Equity: The Heart of the Challenge of Universalising Higher Education Participation}

Placed in broad historical perspective and Martin Trow's prescient formulation in the 1970s of the elite, mass and universal stages of higher education evolution (Trow, 1973), the Bradley review panel endeavoured to formulate the policy settings needed to universalise higher education participation in Australia. This is an undertaking fraught with complexity. Should the set of policy recommendations lack detail or contain internal inconsistencies this is perhaps understandable. And adverse reactions to the proposed transformation of the higher education sector are to be expected too, for if massification brought uncertainties, dilemmas and debate about the preferred character of higher education, universalisation will do so as well, possibly more so.

The current under-representation of people from low socioeconomic status backgrounds and Indigenous people in Australian higher education exemplifies the deep challenges for a universalising campaign such as envisaged by the Bradley review. The achievement of universal participation requires enrolling people in higher education who presently might not consider going to university. These are people who do not believe they can afford the cost or the opportunity cost, who might not see any value in going to university and who might not believe they are "bright" enough to go to university - a belief possibly reinforced by their experience of schooling.

The failure to achieve more socially equitable participation in higher education is sobering. The Australian higher education sector has made genuine efforts to improve equity for at least two decades. Internationally, Australia was a leader in establishing an equity policy framework, and compared with many nations has a well-developed historical database on participation patterns in higher education (James \& Beckett, 2000). Despite extensive policy interventions and widespread equity programs, persistent inequalities remain in the participation in higher education for certain groups of Australians (Centre for the Study of Higher Education, 2008). In broadbrush terms, people from low SES backgrounds are about one-third as likely as people from high SES backgrounds to participate in higher education. The share of university places for people from low SES backgrounds - approximately 15 percent of places, compared with a population reference point of 25 percent $^{1}$ has remained virtually unchanged for 15 years, despite the overall expansion of access to higher education during that period. People from low SES backgrounds are particularly under-represented in the 
professional fields of study for which there is the most competitive entry, and such students make up less than 10 percent of all postgraduate students (James, Bexley et al., 2008).

Australian universities vary considerably in the proportion of students from low SES backgrounds. This is partly due to geographical effects, as well as the effects of competitive selection processes based on the ranking of school achievement. Some Australian universities are notably more successful in enrolling people from low SES backgrounds, reflecting their contexts, patterns of student demand and selection/ recruitment policies and processes. The under-representation of people from low SES backgrounds is most marked in the Group of Eight research-led universities.

Indigenous people are vastly under-represented in higher education on even the most conservative estimates based on population size, population demography and share of university places. For a period there was growth in access for Indigenous people, though this has stalled in recent years. The low access rates and low completion rates for Indigenous people are distinct problems requiring targeted policies and programs. The cumulative effects of long-term educational disadvantage in schooling create particular challenges for social inclusion within the higher education sector. Here the picture is stark. The federal statistics on Indigenous people's participation in higher education reveal extensive under-representation in key areas (Centre for the Study of Higher Education, 2008)

- it is estimated that only five percent of Indigenous people commence higher education by age 18 , compared with close to 30 percent of non-Indigenous people;

- Indigenous people are relatively over-represented in enabling courses and sub-degree programs and vastly under-represented in postgraduate education; and

- Indigenous students' retention and success rates are typically about 80 percent of those of non-Indigenous students, with the university completion rate for Indigenous enrollees at well below 50 percent.

The issues facing the higher education sector in achieving better outcomes for Indigenous people are partly to do with socio-economic status and educational disadvantage in schooling, but there are also significant cultural issues to be addressed in order for stronger relationships to be built between universities and Indigenous people and Indigenous communities.
The Australian equity situation follows international patterns in developed nations (for example, Frenette, 2007; Knowles, 1997; Schuetze \& Slowey, 2002; Skilbeck, 2000). A set of interrelated factors underlies the persistent under-representation of people from low SES backgrounds, and the relative influence of these factors cannot be determined with precision from the available data. Underrepresentation in higher education is partially the result of lower levels of educational achievement in schools, lower educational aspirations and lower school completion rates. For low SES students the Year 12 completion rate is 52 percent for males and 66 percent for females, compared with 75 percent for males and 83 percent for females for high SES students. In remote areas, Australian Year 12 completion is 44 percent for males and 61 percent for females. The Indigenous school completion rate is about half the rate of the total population.

Some simple statistics illustrate the pervasive problem of school achievement. Lower levels of educational achievement in schooling have pervasive effects and are likely to be the precursor for lower aspiration levels. Data from the OECD Programme for International Student Assessment (PISA) reveal substantial differences in achievement on standardised tests for low SES students versus other students. Thus the imbalances in higher education participation probably reflect endemic educational disadvantage that begins in the earliest years of schooling. People from low SES backgrounds are more likely to have lower perceptions of the attainability of a university place, less confidence in the personal and career relevance of higher education, and may be more likely to experience alienation from the cultures of universities (James, 2001, 2002). Financial factors are cited by students as barriers or deterrents to entry to higher education. However, what is not clear from the available data is the extent to which financial considerations, such as the capacity or willingness to pay university fees, the availability of income support while studying, and the opportunity cost in loss of potential income while studying, are inhibitors or barriers to university for people from low SES backgrounds, in comparison with broader aspirational and school achievement factors (Chapman \& Ryan, 2005). Overall, however, it appears that disadvantage with respect to higher education should not be narrowly conceptualised in terms of extrinsic barriers that confront students at or near the point of entry to higher education, such as remoteness or financial cost. There are clearly broader social, educational and cultural factors involved (Siek \& Ainley, 2005). 


\section{Towards A New Conception of Higher Education}

One interpretation of the inability of universities to make inroads into equity is that the problems are simply intractable, the result of endemic social and education conditions well beyond the influence of universities. This is undoubtedly partly true, as the analysis above shows, but equally the lack of gains in equity is due to failure of the higher education sector to adapt to new social circumstances, to establish new attitudes towards student participation and to recognise and build new roles and relationships with communities.

Many aspects of the cultures of Australian universities have adapted little in the past decade and reflect lingering elite era conceptions. Table 1 below, adapted from Brennan's (2004) impressive summary of Trow's original conceptions, captures some of the essential differences between elite, mass and universal higher education that relate particularly to those who participate in higher education and to the nature of their participation. Trow predicted that universal higher education systems would be characterised by features that include:

- more open entry and a focus on "added-value" rather than absolute standards;

- much delayed entry in contrast to the conventional school—higher education linear sequence;

- more modularised curricula; and

- more "dipping in and out" of university education across lifetimes.

Trow's analysis sheds some light on the current predicament in relation to equity and participation in Australian higher education. Many of the mass-to-universal shifts in system and institutional characteristics that he foreshadowed are barely evident. Arguably Australian higher education remains "frozen" between mass and universal conceptions, not only in the thinking within the sector itself but also within wider community attitudes towards the role and value of higher education.

Notions of "talent" and "potential", often firmly class-based, prevail. The idea of meritocratic en try remains firmly enshrined in many universities, the life-work-study nexus and new patterns of student engagement confound conventional modes of delivery, and academic standards are a regular source of hand-wringing.
Table 1 Brennan's summary of Trow's conceptions of elite, mass and universal higher education*

\begin{tabular}{|c|c|c|c|}
\hline & Elite $(0-15 \%)$ & Mass (16-50\%) & Universal (over 50\%) \\
\hline Attitudes to access & $\begin{array}{l}\text { A privilege of birth or } \\
\text { talent or both }\end{array}$ & $\begin{array}{l}\text { A right for those with } \\
\text { certain qualifications }\end{array}$ & $\begin{array}{l}\text { An obligation for the } \\
\text { middle and upper classes }\end{array}$ \\
\hline $\begin{array}{l}\text { Functions of higher } \\
\text { education }\end{array}$ & $\begin{array}{l}\text { Shaping mind and } \\
\text { character of ruling class; } \\
\text { preparation for elite } \\
\text { roles }\end{array}$ & $\begin{array}{l}\text { Transmission of skills; } \\
\text { preparation for broader } \\
\text { range of technical and } \\
\text { economic elite roles }\end{array}$ & $\begin{array}{l}\text { Adaptation of "whole } \\
\text { population" to rapid } \\
\text { social and technological } \\
\text { change }\end{array}$ \\
\hline $\begin{array}{l}\text { Curriculum and forms } \\
\text { of instruction }\end{array}$ & $\begin{array}{l}\text { Highly structured in } \\
\text { terms of academic or } \\
\text { professional } \\
\text { conceptions of } \\
\text { knowledge }\end{array}$ & $\begin{array}{l}\text { Modular, flexible and } \\
\text { semi-structured } \\
\text { sequence of courses }\end{array}$ & $\begin{array}{l}\text { Boundaries and } \\
\text { sequences break down; } \\
\text { distinctions between } \\
\text { learning and life break } \\
\text { down }\end{array}$ \\
\hline The student "career" & $\begin{array}{l}\text { "sponsored" after } \\
\text { secondary school; } \\
\text { works uninterruptedly } \\
\text { until gains degree }\end{array}$ & $\begin{array}{l}\text { Increasing numbers } \\
\text { delay entry; more drop } \\
\text { out }\end{array}$ & $\begin{array}{l}\text { Much postponement of } \\
\text { entry, softening of } \\
\text { boundaries between } \\
\text { formal education and } \\
\text { other aspects of life; } \\
\text { term-time working }\end{array}$ \\
\hline $\begin{array}{l}\text { Institutional } \\
\text { characteristics }\end{array}$ & $\begin{array}{l}\text { - Homogenous with } \\
\text { high and common } \\
\text { standards } \\
\text { - Small residential } \\
\text { communities } \\
\text { - Clear and } \\
\text { impermeable } \\
\text { boundaries }\end{array}$ & $\begin{array}{l}\text { - Comprehensive with } \\
\text { more diverse standards; } \\
\text {-“Cities of intellect” - } \\
\text { mixed residential/ } \\
\text { commuting } \\
\text { - Boundaries fuzzy and } \\
\text { permeable }\end{array}$ & $\begin{array}{l}\text { - Great diversity with no } \\
\text { common standards } \\
\text { - Aggregates of people } \\
\text { enrolled some of whom } \\
\text { are rarely or never on } \\
\text { campus } \\
\text { - Boundaries weak or } \\
\text { non-existent }\end{array}$ \\
\hline Academic standards & $\begin{array}{l}\text { Broadly shared and } \\
\text { relatively high (in } \\
\text { meritocratic phase) }\end{array}$ & $\begin{array}{l}\text { Variable; } \\
\text { system/institution } \\
\text { "become holding } \\
\text { companies for quite } \\
\text { different kinds of } \\
\text { academic enterprises" }\end{array}$ & $\begin{array}{l}\text { Criterion shifts from } \\
\text { "standards" to "value } \\
\text { added" }\end{array}$ \\
\hline Access and selection & $\begin{array}{l}\text { Meritocratic } \\
\text { achievement based on } \\
\text { school performance }\end{array}$ & $\begin{array}{l}\text { Meritocratic plus } \\
\text { "compensatory } \\
\text { programs" to achieve } \\
\text { equality of opportunity }\end{array}$ & $\begin{array}{l}\text { "open", emphasis on } \\
\text { "equality of group } \\
\text { achievement" (class, } \\
\text { ethnic) }\end{array}$ \\
\hline
\end{tabular}

${ }^{*}$ Adapted from Brennan (2004, p. 24) 
Trow's conceptions of the mass-to-universal transition may not capture all of the facets of the policy dialogue in Australia around the Bradley review, yet they provide remarkable insights into the issues emerging for universities and higher education systems in developed nations. There is great pressure on universities to be more relevant and to demonstrate their contribution to social, cultural and economic development. The transition to universal participation and greater social inclusion will involve a debate about the roles and purposes of higher education that will confront fundamental values. The characteristics and values of a universal higher education system are necessarily in tension with those of an elite or mass system. These value tensions will need to be painfully worked through as universities endeavour to be both excellent and equitable, charitable and commercial, regional and international, open and flexible, yet firmly adhering to standards.

\section{Five Interlocking Pre-conditions for Achieving Universal Participation}

If a new paradigm for higher education is needed to widen participation in higher education on a major scale, what might it look like? Broadly, it would involve forms of higher education that create vastly more flexible relationships with communities: more open and diverse entry and exit points, more flexible delivery modes, and more flexible forms of recognition of learning. What follows is an analysis hypothesised around five interlocking or interwoven pre-conditions for achieving expansion and equity on the scale proposed by the Bradley review panel. Conditions 1 and 2 are in many ways self-evident. Conditions 3 through 5 are deeply interdependent and have vastly different ramifications for individual institutions depending on their history, location and market position. For each of these pre-conditions, attitudes and values, both within and outside universities, will be highly influential in determining the nature of outcomes. Conditions 3 through 5 are not merely a matter of funding and federal policy; these require major shifts in institutional policies and priorities, and new academic cultures and attitudes. Pre-condition 3 is pivotal.

1. Infrastructure: New campuses and new ways of utilising tertiary education infrastructure

Needless to say, the proposed expansion of participation raises questions about the capacity of existing infrastructure. Many universities already have decaying and obsolete infrastructure that is urgently in need of renewal. Various models have already been floated for accommodating larger number of students, including the creation of new campuses or institutions in outer-urban areas, the utilisation of TAFE (Technical and Further Education) colleges (some of which are already degree-granting), and the more intensive use of existing university campuses through, say, summer semesters. The latter raises interesting possibilities but is contingent upon individual institutions opting to choose a "higher-volume" strategy. Not all will be inclined to do so, of course, and the institutions for which there is presently the highest demand, the research-led universities, may be the least willing to increase their student numbers.

2. Funding: New fee policies, new forms of student income support, new possibilities for term-time working integrated with study

Universal higher education requires a new funding paradigm: for tuition, delivery and student income support. The Bradley review's recommendation for entitlements to Commonwealth-supported higher education for eligible students lacked sufficient detail in its original formulation for its economics to be fully understood. "Eligibility" appears to be defined in terms of institutional willingness to enrol students, potentially leaving the Commonwealth with highly unpredictable patterns of liability from year to year. Putting these uncertainties aside, it is obvious that a large injection of revenue will be needed to fund expansion and equity on the scale proposed by the Bradley review, if high-volume low-quality provision is to be avoided. In the absence of price deregulation, which the Bradley review panel did not entertain, the public universities remain highly constrained in their capacity to improve their revenue base. There are questions about the willingness and the capacity of the government to fund system expansion adequately, particularly in the context of the global financial crisis. The massification of Australian higher education has been partly funded by the fees from international students, many from developing nations. This is unlikely to be an option for universalising domestic participation, both on practical and moral grounds.

From the student perspective, the costs of going to university, real and perceived, will significantly affect demand and may undermine national aspirations for wider participation. Progress towards universal participation is dependent on personal cost-benefit decisions, individuals weighing-up the direct costs and perceived opportunity costs associated with going to university. While arguably the Higher 
Education Contribution Scheme (HECS) has been an effective mechanism for delaying individual payment and funding system expansion, it has not been without its critics. Aversion to debt appears commonplace, and whether there are differential effects across social classes is not clear. Living costs while studying are also a significant factor. In 2006 the Centre for the Study of Higher Education undertook a major national study of student finances for Universities Australia (James et al., 2007). The study found that, compared with the previous national study in 2000 , there was a greater reliance on paid work, more students were taking out loans and more students reported that paid work was having an adverse effect on their studies. The survey found that many students were in stressful financial positions. A large proportion of students lacked adequate financial support and many were highly anxious about "making ends meet" on a week-to-week basis. There was much anxiety about accumulating debt. The ways forward here are not obvious. It seems likely that in a universal participation system at least some institutions will fully embrace the new patterns of student term-time working, in some cases integrating these with curricula, and others will adopt study-work sandwiching as the norm. Others may increase the opportunities for paid on-campus work, an area presently poorly exploited in Australia.

3. Institutional differentiation: Genuine mission diversification

Ultimately, the extent and nature of institutional differentiation, and how this relates to student recruitment/selection and curricula, will be central to achieving national goals for expansion and equity. Institutional mission differentiation is politically complex because it is contingent on both the national policy settings and institutional cultures. The international experience shows that while universities respond to external factors, these responses are strongly mediated by their internal cultures. To date there has been little evidence of willingness for major mission differentiation among Australian universities and the topic is politically charged. Though there is a wave of curriculum renewal taking place, the teaching-research nexus remains sacrosanct. The idea of teaching-only institutions remains contentious and was explicitly rejected by the Bradley review panel.

A universal higher education system will require diversification across student selection, curricula and teaching and learning methodologies. Australian universities lie along a continuum from "recruiters" to "selectors" in their student admission orientations. With
Bradley's expansion-equity coupling, the challenge for the recruiter universities will be to develop new higher education markets where presently these do not exist; the challenge for selector universities, where demand exceeds supply, will be to identify educationally disadvantaged students who have high academic potential, while at the same time determining objective and fair ways of denying admission to students who have already demonstrated high academic potential.

Trow did not suggest that the universal and mass stages of system evolution would entirely replace the elite form. The nature and extent of institutional differentiation in mission and curricula, within a national framework for threshold academic standards, will be a central determinant of Australia's success in developing an educationally effective universal higher education system. The nation's success in achieving horizontal institutional differentiation will be the key, but this is without doubt a delicate policy exercise.

4. Open entry: New conceptions of merit, less reliance on school achievement ranking, new pathways for adults

Universal higher education involves enrolling students in university who are not ready for higher education, as it is currently perceived. In a universal system, universities must accept that one their roles in to address shortfalls in schooling for some people. This reality causes discomfort, as it confronts implicit and explicit assumptions about merit, preparedness and standards. Meritocratic entry lives on, albeit more powerfully in some universities than others. Broadly, student admission in Australian higher education sector continues to operate in the main part on a "merit" + "compensation for equity" paradigm. The ranking of school achievement maintains a firm grip on university selection practices. To universalise participation, this grip needs to be loosened and new pedagogical understandings developed to deal with students who are not suitably prepared for higher education on present conceptions of readiness. As with other aspects of system universalising, the effects will be experienced quite differently across institutions according to their niches in the market and distinctive missions.

5. Curriculum innovation and diversification, strategies for retention in first year

The purposes, formats and structures of curricula will need to adapt and diversify. This is essential to ensure accessibility and relevance for a wider group of people, and also to stem attrition in the first year, which 
presently is around 20 percent nationally and in some universities over 30 percent. The curriculum is one of the sites of the dynamic tensions that universalising will create. For example, while there is a case for more modular curricula - since long-haul degrees are a substantial impediment to re-engagement for adults - modularisation creates dilemmas for educational coherence.

The Bradley review's recommendations are likely to accelerate and consolidate an unprecedented phase of curriculum renewal underway in Australian universities. ${ }^{2}$ Curricula seem likely to remain in a state of flux as societal needs change rapidly and institutional competition heightens - the era of "steady-state" curricula seems to be over. The reasons for the renewed attention to the purposes and structure of the curriculum and the desired outcomes for graduates include:

- new patterns of student engagement;

- an increasing market-orientation in the Australian higher education sector and pressure for institutional diversification and distinctiveness;

- the intensification of interest in interdisciplinary education; and

- the intensification of interest in workplace learning, community engagement and knowledge transfer.

The Bradley review did not recommend the introduction of pre-bachelors degree "foundation" awards, though there may be an argument for these in a universal system. In the absence of a new award category there is the risk of negative community perceptions developing around undifferentiated, low-status bachelors degrees and an accompanying pressure for credential creep. There are already signs that professional training will increasingly move to graduate level studies.

The changes foreshadowed for the higher education sector will have a profound impact on the status and role of vocational education and training. The Bradley review argues for more cross-sectoral engagement - greater collaboration between Vocational Education and Training (VET) and Higher Education sectors and a more integrated or seamless tertiary education sector. Certainly the problems of equity are decidedly cross-sectoral in character, and advancing equity requires partnerships, cooperation and collaboration between providers across all sectors. The renewal of the Australian Qualifications Framework, as proposed by Bradley, would be a helpful step forward if it were to remove sectoral divides and hierarchies.

\section{Conclusion}

Can the Australian higher education sector successfully implement the Bradley reform agenda? The changes will need to be profound, for the twin objectives of expansion and social inclusion affect so many aspects of the character of universities and their relationships with communities. The preceding analysis is barely a sketch of the issues and possibilities as Australia begins a 10-15 year process of creating a universal higher education system.

The idea of universal participation challenges deeply-held assumptions about the nature and purposes of higher education. The debate is likely to be intense, and significant social, political and educational tensions seem inevitable as the nation and the university sector develop new conceptions of the structures of a tertiary education system suited to universal participation. There will be much polemic about academic standards, polarized views on the importance of the teaching-research nexus, and disagreement on the issues of fee deregulation and institutional differentiation. The federal policy settings need to foster a more diverse yet universally high quality higher education sector.

Participation in higher education can be conceived under the rubric of alternative policy constructs, such as social equity, national economic development and lifelong learning. The Bradley review has framed the argument for universal participation in terms of national economic development and international competitiveness. But this argument does not in itself provide the incentive for individual participation. The analysis in this article has been largely of supply-side issues; the demand-side requires further treatment in its own right. How, and in what ways, greater demand for higher education can be generated is unclear, given that demand was rising only slowly prior to the global financial crisis. Part of the universalising process, if it is to be successful, must involve a considerable shift in community attitudes towards the value of higher education and the obligations for individuals to participate in formal education across all career and life stages.

\section{Notes}

1. The policy framework for socioeconomic status uses three groupings using a postcode index calculated on census income data. Postcodes are ranked according to the educational and occupational characteristics of residents using the SEIFA (Socioeconomic Indexes for Areas) index. The group of postcodes at the lowest end of the ranking which contain the 
first 25 percent of the population are allocated a low SES classification, those containing the next 50 percent of the population a medium SES classification and the final 25 percent a high SES classification.

2. The University of Melbourne was one of the first universities to initiate macro curriculum reformation with the introduction in 2008 of the "Melbourne Model", a curriculum structure comprising 3-year liberal or generalist bachelors degrees and 2-year professional masters degrees or research masters degrees.

\section{References}

Brennan, J. (2004). The social role of the contemporary university: Contradictions, boundaries and change. In Ten years on: Changing education in a changing world (pp. 22-26). Milton Keynes: The Open University, Center for Higher Education Research and Information.

Candy, P., Crebert, G., \& O'Leary, J. (1994). Developing lifelong learners through undergraduate education. Commissioned Report No. 28, National Board of Employment, Education and Training. Canberra: Australian Government Publishing Service.

Centre for the Study of Higher Education (CSHE). (2008). Participation and equity. Canberra: Universities Australia.

Chapman, B., \& Ryan, C. (2005). The access implications of income-contingent charges for higher education: Lessons from Australia. Economics of Education Review, 24, 491-512.

Corver, M. (2005). Young participation in higher education. Bristol: Higher Education Funding Council for England.

DEEWR (Department of Education, Employment and Workplace Relations). (2008). Review of Australian higher education: Final report. Canberra: Australian Government Publishing Service.

Frenette, M. (2007). Why are youth from lower-income families less likely to attend university? Evidence from academic abilities, parental influences, and financial constraints. Ottawa: Analytical Studies Branch Research Paper Series. Statistics Canada.

James, R., \& Beckett, D. (2000). Higher education and lifelong learning: An Australian perspective. In H. Schuetze \& M. Slowey (Eds.), Higher education and lifelong learning: International perspectives on change (pp. 73-194). London: Routledge/Falmer.

James, R., \& McInnis, C. (2005). Equity policy in Australian higher education: A case of policy stasis. In A. Gornitzka, M. Kogan \&
A. Amaral (Eds.), Reform and change in higher education dynamics: Analysing policy implementation (pp. 227-244). Dordrecht: Springer.

James, R. (2001). Participation disadvantage in Australian higher education: An analysis of some effects of geographical location and socioeconomic status. Higher Education, 42, 455-472.

James, R. (2002). Socioeconomic background and higher education participation: An analysis of school students' aspirations and expectations. Canberra: Department of Education, Science and Training, Commonwealth of Australia.

James, R., Bexley, E. et al. (2008). Participation and equity. Canberra: Universities Australia.

James, R., Bexley, E., Devlin, M., \& Marginson, S. (2007). Australian university student finances 2006. Final report of a national survey of students in public universities. Canberra: Universities Australia.

Knowles, J. (1997, September). The influence of socioeconomic status on aspirations to enter higher education: School pupils' awareness, understanding and expectations of higher education. Paper presented at the British Educational Research Association Annual Conference, University of York.

Rose, S. J., \& Carnevale, A. P. (2003). Socioeconomic status, race/ethnicity, and selective college admissions. New York: The Century Foundation.

Schuetze, H. G., \& Slowey, M. (2002). Participation and exclusion: A comparative analysis of non-traditional students and lifelong learners in higher education. Higher Education, 44, 309-327.

Siek, T. K., \& Ainley, J. (2005). Attitudes, intentions and participation. Longitudinal surveys of Australian youth. Research Report 41. Melbourne: Australian Council for Educational Research.

Skilbeck, M. (2000). Access and equity in higher education: An international perspective on issues and strategies. Dublin: The Higher Education Authority.

Trow, M. (1973). Problems in the transition from elite to mass higher education. California: Carnegie Commission on Higher Education.

West, R. (1998). Learning for life: Review of higher education financing and policy (The West Review). Canberra: Australian Government Publishing Service. 


\section{The author}

Richard James is Director of the Centre for the Study of Higher Education and a Professor of Higher Education at the University of

Melbourne. His research interests focus on higher education policy and he has published widely, including on the first year experience, equity, student finances, quality assurance and academic standards. 